\title{
SPL Equivalence Codes Terminology
}

National Cancer Institute

\section{Source}

National Cancer Institute. SPL Equivalence Codes Terminology. NCI Thesaurus. Code C111660.

Terminology used for representation of the information on pharmaceutical product equivalence codes in the framework of the Structured Product Labeling documents. 